\title{
Effect of GGBS and curing temperature on microstructure characteristics of lightweight geopolymer concrete
}

\author{
Hilal El-Hassan ${ }^{1, *}$, Najif Ismail $^{1}$, Sara Al Hinaii ${ }^{1}$, Asma Alshehhi ${ }^{1}$, Noor Al Ashkar ${ }^{1}$ \\ ${ }^{1}$ Department of Civil and Environmental Engineering, United Arab Emirates University, Al \\ Ain, United Arab Emirates, P.O. Box 15551
}

\begin{abstract}
Cement replacement by supplementary cementitious materials has been gaining momentum as a sustainable mechanism to reduce greenhouse gas emissions while also recycling industrial by-products. This paper presents the development and microstructure characterization of fly ash-based lightweight geopolymer concrete incorporating ground granulated blast furnace slag (GGBS). Concrete samples were prepared with $0 \%, 25 \%$ and $50 \%$ GGBS replacement and cured at $30^{\circ} \mathrm{C}, 60^{\circ} \mathrm{C}$, and ambient temperature. While dune sand and lightweight expanded clay were used as aggregates, a mixture of sodium silicate and sodium hydroxide served as the alkaline activation solution. Microstructure evaluation was carried out at 7 and 28 days employing scanning electron microscopy (SEM), Fourier transform infrared spectroscopy (FTIR), and differential scanning calorimetry (DSC). Residual fly ash and GGBS were identified in the concrete and bonded to geopolymeric reaction products. The microstructure highlighted the formation and coexistence of aluminosilicate hydrate and aluminum-rich calcium silicate hydrate with traces of sodium. Subsequent polymerization was also verified by an increase in FTIR and DSC peaks.
\end{abstract}

\section{Introduction}

The global production of concrete is approximately one cubic meter per capita, making it one of the largely produced materials on earth [1]. It is a composite material mainly comprising cement and coarse and fine aggregates. Portland cement is manufactured by mixing limestone and clay in specific proportions at elevated temperatures. The process consumes $1.6 \mathrm{~kg}$ of raw material, requires $3.7 \mathrm{MJ}$ of energy, and emits $1 \mathrm{~kg}$ of $\mathrm{CO}_{2}$ per $\mathrm{kg}$ of cement produced $[2,3]$. In fact, the cement industry alone is accountable for $5-7 \%$ of the global $\mathrm{CO}_{2}$ emissions $[4,5]$, leading to an increase in the concentration of $\mathrm{CO}_{2}$ in the atmosphere $[6,7]$. As a result, cement production is becoming an increasing global pressing issue from an ecological, social, and environmental standpoint.

To alleviate consumption of natural resources and emission of $\mathrm{CO}_{2}$ from cement manufacturing, scientists and environmentalists propose the incorporation of supplementary cementitious material (SCMs) in concrete mixes. In most cases, these SCMs are pozzolanic

\footnotetext{
*Corresponding author: helhassan@uaeu.ac.ae
} 
and non-pozzolanic industrial solid waste. Fly ash, a residual by-product from the combustion of coal, is highlighted as a primary replacement to ordinary Portland cement (OPC) in concrete due to its pozzolanic properties and global abundance. In one technique, it served as the main binder in an inorganic geopolymer concrete (GPC). The aluminosilicate material was activated through mixing with an alkaline solution of sodium silicate $\left(\mathrm{Na}_{2} \mathrm{SiO}_{3}\right)$ and potassium or sodium hydroxide $(\mathrm{KOH}$ or $\mathrm{NaOH})$. When compared to OPC, the geopolymer technology could reduce carbon dioxide emissions up to 80-90\% [8]. In addition, fly ashbased GPC experienced improved early strength, low permeability, excellent resistance to chemical attacks, good freezing-thawing cycles and enhanced thermal durability in high temperature environments [9-14]. Further work investigated the incorporation of other SCMs, as ground granulated blast-furnace slag (GGBS), in geopolymer concrete [15-18]. The microstructure provided evidence of the coexistence of aluminosilicate gel and calcium silicate hydrate (C-S-H) gel [16, 19]. The geopolymeric matrix also highlighted the presence of unreacted fly ash as a pore-filling material, leading to a good bond between the geopolymer paste and aggregate at the interfacial transition zone (ITZ) [20, 21]. In addition, higher GGBS replacement presented a more compact and less porous concrete [15].

Despite the research efforts in studying the microstructure, the results were somewhat lacking. The combined effect of curing temperature, multiple aluminosilicate sources, dune sand addition, and lightweight aggregate use on the microstructure of geopolymer concrete has not been investigated yet. As such, this research aims to study the effect of $25 \%$ and $50 \%$ fly ash replacement by GGBS and curing temperatures of $30^{\circ} \mathrm{C}, 60^{\circ} \mathrm{C}$, and outdoor ambient conditions on the microstructure of lightweight GPC. To achieve a sustainable concrete mix design, locally-available lightweight expanded clay aggregates (LECA) and dune sand were used as aggregates. The morphological changes and reaction products were characterized in GPC by employing scanning electron microscopy (SEM), Fourier transform infrared spectroscopy (FTIR), and differential scanning calorimetry (DSC). The proposed work could provide valuable information on the behavior of GPC to validate their use in the building and construction industry.

\section{Materials and methods}

\subsection{Concrete sample preparation}

Geopolymer concrete mixes were prepared with locally-available material including GGBS, fly ash, dune sand, and expanded clay aggregates. The chemical composition of the asreceived materials were determined using X-ray fluorescence (XRF) and are shown in Table 1. The morphology of constituent materials is presented as SEM micrographs in Fig. 1. The alkaline activator solution was prepared two hours prior to incorporation in the GPC mix by mixing sodium hydroxide (concentration $=18 \mathrm{M}$ ) with sodium silicate at solid and solution ratios of $1: 1$ and 1:1.5, respectively. Table 2 presents the chemical composition of each solution.

For this study, 100-mm concrete cubes were cast. The mixture proportions, shown in Table 3, were designed following a procedure for geopolymer concrete [22]. Three mixes were prepared while varying the percent replacement of fly ash by GGBS $(0 \%, 25 \%$, and $50 \%$ ). By mass, the ratio of dune sand-to-LECA was fixed to 1.73 , while that of total aggregate-to-cementitious material was 3.27. The alkali solution-to-cementitious material ratio was set to 0.4 for all mixes. Water was added to the mixes to improve the workability of fresh geopolymer concrete. The expanded clay aggregates were used at surface-saturated dry (SSD) condition to minimize water or alkali solution absorption during mixing. The raw 
materials were mixed in a drum mixer, and samples were compact formed on a vibrating table to simulate industry practice. Samples were then demolded and cured for 24 hours at outside ambient temperature (A), $30^{\circ} \mathrm{C}$, and $60^{\circ} \mathrm{C}$. Later, all concrete specimens were left outside to cure until testing. Samples were labeled N-T based on the mix number $(1,2,3)$ and curing temperature $\left(\mathrm{A}, 30^{\circ} \mathrm{C}\right.$, or $\left.60^{\circ} \mathrm{C}\right)$. It is worth noting that curing condition $\mathrm{A}$, outside ambient temperature, was proposed to study the possibility of preparing GPC without the need of a controlled environment or furnace.

Table 1. Chemical composition of as-received materials.

\begin{tabular}{|c|c|c|c|c|c|c|c|c|}
\hline \multirow{2}{*}{ Material } & \multicolumn{7}{|c|}{ Constituent (\%) } \\
\cline { 2 - 9 } & $\mathbf{S i O}_{\mathbf{2}}$ & $\mathbf{A l}_{2} \mathbf{O}_{\mathbf{3}}$ & $\mathbf{F e}_{2} \mathbf{O}_{3}$ & $\mathbf{C a O}$ & $\mathbf{M g O}$ & $\mathbf{N a}_{2}$ & $\mathbf{K}_{2}$ & LOI \\
\hline Fly ash & 48.0 & 23.1 & 12.5 & 3.3 & 1.5 & - & - & 1.1 \\
\hline GGBS & 34.7 & 14.4 & 0.8 & 42.0 & 6.9 & - & - & 1.1 \\
\hline Dune sand & 63.9 & 3.0 & 0.7 & 14.1 & 1.3 & 0.4 & 1.1 & - \\
\hline
\end{tabular}

Table 2. Chemical composition of alkali solutions.

\begin{tabular}{|c|c|c|c|c|c|}
\hline Solution & $\begin{array}{c}\text { Density } \\
\left(\mathbf{k g} / \mathbf{m}^{3}\right)\end{array}$ & $\begin{array}{c}\text { Solids } \\
(\%)\end{array}$ & $\begin{array}{c}\mathbf{H}_{2} \mathbf{O} \\
(\mathbf{\%})\end{array}$ & $\begin{array}{c}\mathbf{N a}_{2} \mathbf{O} \\
(\mathbf{\%})\end{array}$ & $\begin{array}{c}\mathbf{S i O}_{2} \\
(\mathbf{\%})\end{array}$ \\
\hline $\mathrm{NaOH}$ & 1380 & 37.5 & 62.5 & 8.9 & 28.6 \\
\hline $\mathrm{Na}_{2} \mathrm{SiO}_{3}$ & 1610 & 51.8 & 48.2 & 40.2 & 0 \\
\hline $\mathrm{NaOH}+\mathrm{Na}_{2} \mathrm{SiO}_{3}$ & 1518 & 43.3 & 56.7 & 21.5 & 17.1 \\
\hline
\end{tabular}

Table 3. Mixture proportions of geopolymer concrete mixes.

\begin{tabular}{|c|c|c|c|c|c|c|c|c|}
\hline \multirow{2}{*}{ Mix \# } & \multicolumn{7}{|c|}{ Component $\left(\mathbf{k g} / \mathbf{m}^{\mathbf{3}}\right.$ ) } \\
\cline { 2 - 9 } & Fly Ash & GGBS & $\begin{array}{l}\text { Dune } \\
\text { Sand }\end{array}$ & LECA & $\mathbf{N a O H}$ & $\mathbf{N a}_{2} \mathbf{S i O}_{3}$ & $\begin{array}{c}\text { Added } \\
\text { Water }\end{array}$ & Total \\
\hline 1 & 302 & 0 & 628 & 364 & 48 & 73 & 5 & 1420 \\
\hline 2 & 227 & 74 & 628 & 364 & 48 & 73 & 12 & 1426 \\
\hline 3 & 151 & 148 & 628 & 364 & 48 & 73 & 20 & 1432 \\
\hline
\end{tabular}

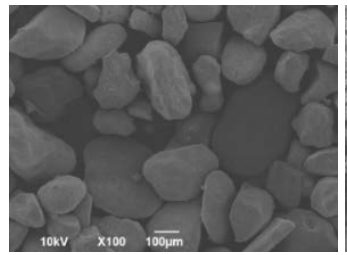

(a)

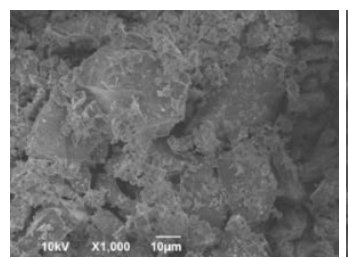

(c)

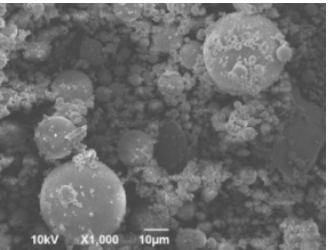

(b)

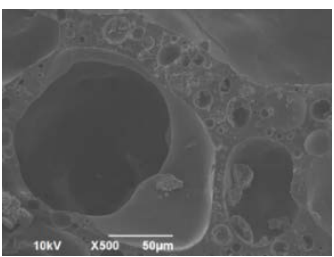

(d)

Fig. 1. SEM of as-received dune sand (a), fly ash (b), GGBS (c), and LECA (d). 


\subsection{Microstructure evaluation}

\subsubsection{Scanning electron microscopy}

The morphology of produced geopolymer concrete specimens was investigated after 7 and 28 days using scanning electron microscopy (SEM). Test samples were extracted from untested concrete with typical flat surface and coated with a gold layer to ensure electron conductivity. High-vacuum SEM mode and energy-dispersive X-ray (EDX) analysis were employed (JEOL-JSM 6390A) to examine the changes in concrete microstructure and morphology.

\subsubsection{Fourier transform infrared spectroscopy}

Fourier transform infrared (FTIR) spectroscopy was employed to evaluate the degree of polymerization reaction and identify the reaction products after 7 and 28-day subsequent curing. Specimens were prepared by mixing potassium bromide $(\mathrm{KBr})$ with finely-ground geopolymer concrete at a 2:1 ratio. The FTIR spectra were obtained in transmittance mode from 400 to $4000 \mathrm{~cm}^{-1}$ at a resolution of $1 \mathrm{~cm}^{-1}$ using a Varian 3100 FT-IR spectrometer.

\subsubsection{Differential scanning calorimetry}

Powdered samples were examined by differential scanning calorimetry (DSC) using a DSC Q200. Specimens, on the range of $10 \mathrm{mg}$, were packed and sealed into aluminum containers in preparation for testing. DSC curves were obtained by heating the samples from $20^{\circ} \mathrm{C}$ to $550^{\circ} \mathrm{C}$ at a heating rate of $10^{\circ} \mathrm{C} / \mathrm{min}$ under a constant flow of nitrogen gas $(50 \mathrm{ml} / \mathrm{min})$. Resulting curves showed the heat flow between the sample and reference pan as a function of temperature.

\section{Results and discussion}

\subsection{SEM Analysis}

The effect of replacing cement by GGBS and alternating the curing temperature on the morphology of GPC was examined using SEM imaging. Fig. 2 shows the micrograph of mix 1 after 7-day curing. Aluminosilicate glass represented in unreacted fly ash spheres are heavily dispersed throughout the microstructure of concretes regardless of curing temperature. The ambient-cured sample (1-A) presented some microcracks on the order of 3 $\mu \mathrm{m}$. The aggregate-geopolymer paste interface of concrete mix 2 appeared to be weakly bonded, evidenced by the crack propagation along the interfacial transition zone. Upon the replacement of $25 \%$ fly ash with GGBS, concrete micrographs of Fig. 3 showed agglomerated angular slag particles with some fly ash spheres attached to the reaction products. It seemed that while fly ash particles did not dissolve in the mix, the geopolymerization reaction occurred on the surface or external shell only [23]. Further incorporation of GGBS produced an intermix of source materials in the paste within a diverse matrix as shown in Fig. 4. It is clear that the addition of water to improve workability formed a more porous concrete microstructure. 


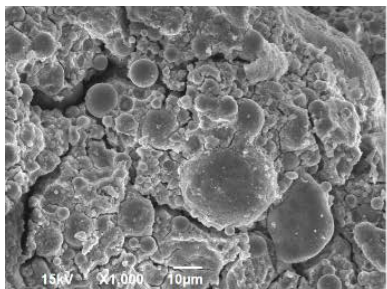

(a)

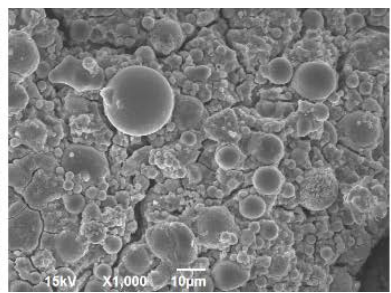

(b)

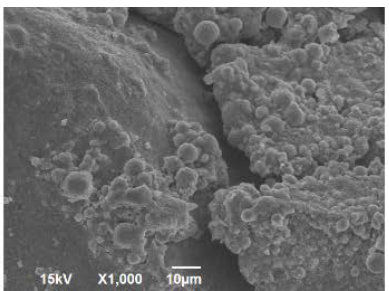

(c)

Fig. 2. Micrograph of mix 1 after 7 days curing at (a) ambient conditions, (b) $30^{\circ} \mathrm{C}$, (c) $60^{\circ} \mathrm{C}$.

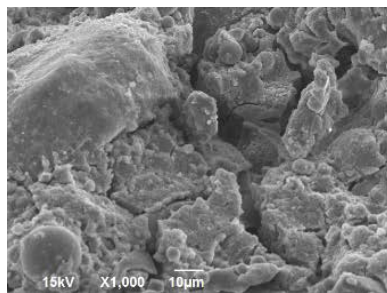

(a)

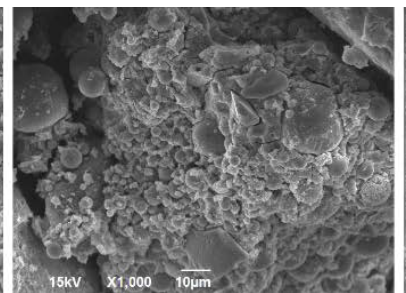

(b)

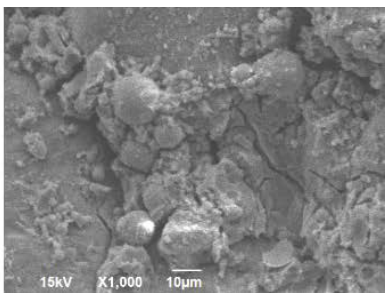

(c)

Fig. 3. Micrograph of mix 2 after 7 days curing at (a) ambient conditions, (b) $30^{\circ} \mathrm{C}$, and (c) $60^{\circ} \mathrm{C}$.

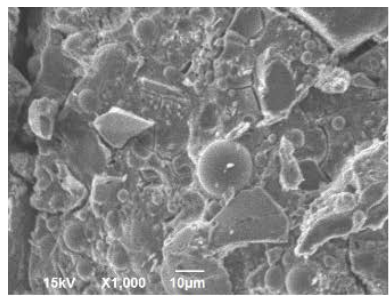

(a)

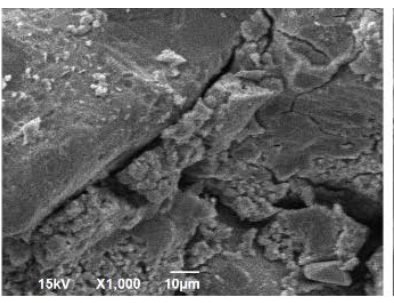

(b)

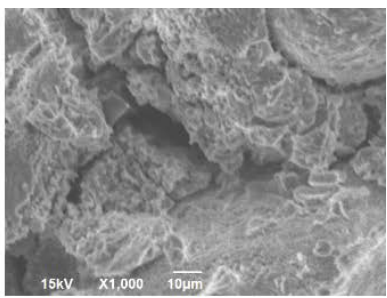

(c)

Fig. 4. Micrograph of mix 3 after 7 days curing at (a) ambient conditions, (b) $30^{\circ} \mathrm{C}$, (c) $60^{\circ} \mathrm{C}$.
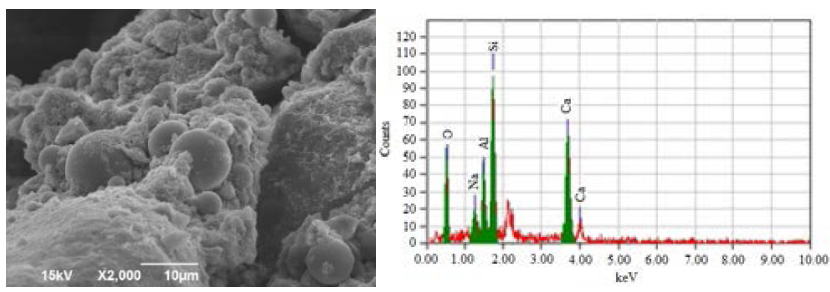

Fig. 5. SEM micrograph (a) and EDX spectrum (b) of specimen $3-60^{\circ} \mathrm{C}$ after 7 days curing.

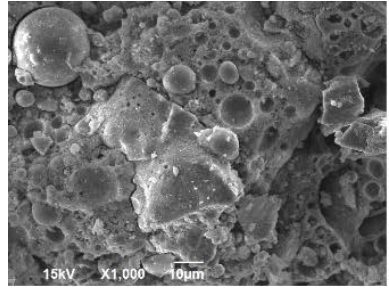

(a)

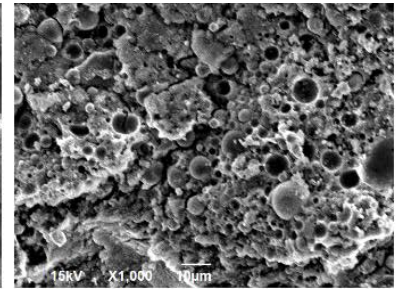

(b)

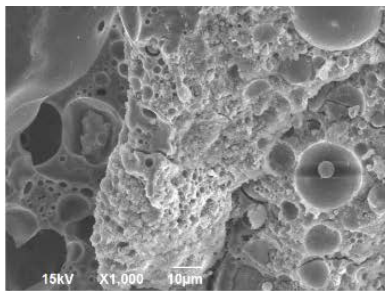

(c)

Fig. 6. Micrograph of mix 1 after 28 days curing at (a) ambient conditions, (b) $30^{\circ} \mathrm{C}$, and (c) $60^{\circ} \mathrm{C}$. 


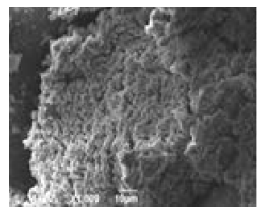

(a)

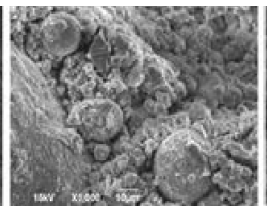

(b)

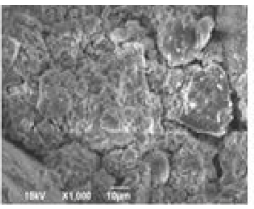

(c)

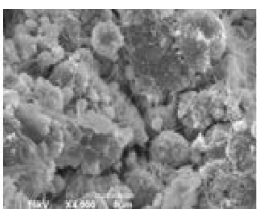

(d)

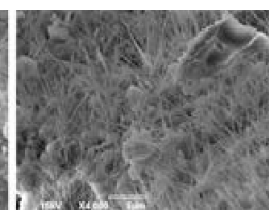

(e)

Fig. 7. Micrograph of mix 2 after 28 days curing at at (a) ambient conditions, (b) $30^{\circ} \mathrm{C}$ (Mag. 1000), (c) $60^{\circ} \mathrm{C}$ (Mag. 1000 ), (d) $30^{\circ} \mathrm{C}$ (Mag. 4000), (e) $60^{\circ} \mathrm{C}$ (Mag. 4000).

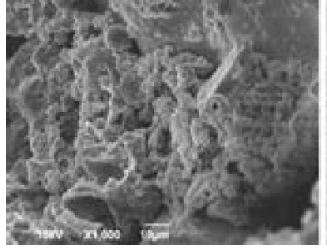

(a)

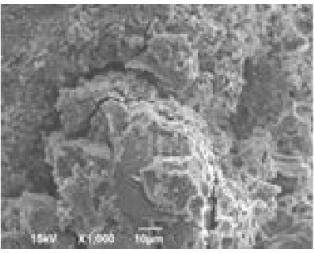

(b)

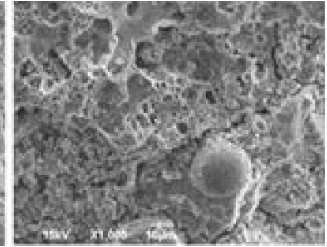

(c)

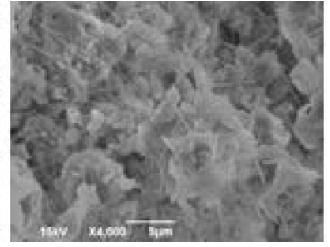

(d)

Fig. 8. Micrograph of mix 3 after 28 days curing at (a) ambient conditions, (b) $30^{\circ} \mathrm{C}$ (Mag. 1000), (c) $60^{\circ} \mathrm{C}$, (d) $30^{\circ} \mathrm{C}$ (Mag. 4000)

EDX analysis was employed over a GPC surface area to characterize the reaction products. Fig. 5(a) and 5(b) depict the SEM micrograph and corresponding EDX spectrum of concrete 3-60. It highlights the presence of calcium $(\mathrm{Ca})$, silicon $(\mathrm{Si})$, sodium $(\mathrm{Na})$, aluminum $(\mathrm{Al})$, and oxygen $(\mathrm{O})$, indicating the coexistence of an aluminium-modified $\mathrm{C}-\mathrm{S}-$ $\mathrm{H}$ gel with $\mathrm{N}-\mathrm{A}-\mathrm{S}-\mathrm{H}$ gel [15]. It was however difficult to distinguish $\mathrm{C}-\mathrm{S}-\mathrm{H}$ and $\mathrm{N}-\mathrm{A}-\mathrm{S}-$ $\mathrm{H}$ gels through their morphology.

Micrographs of Figures 6(a) to 6(c) study the morphology of mix 1 at the age of 28 days. With further integration of fly ash spheres into the geopolymer paste, it is clear that the geopolymerization reaction developed during subsequent curing. Microcracks, although still present, have decreased to the range of $1 \mu \mathrm{m}$. A more grainy microstructure was observed in Fig. 7 for concretes with 25\% GGBS replacement. Fly ash spheres were coated with glassy reaction products. Ettringite was identified at higher magnifications as shown in Fig. 7(d) and 7(e). As it was also detected in mix 3 (Fig. 8(c)), it was confirmed to be a reaction product that formed in concretes cured at $30^{\circ} \mathrm{C}$ and $60^{\circ} \mathrm{C}$ during subsequent curing.

\subsection{FTIR analysis}

The FTIR spectra of three geopolymer concrete mixes at the age of 7 days is shown in Fig. 9. The stretching vibration mode of $\mathrm{Si}-\mathrm{O}-\mathrm{T}$ ( $\mathrm{T}$ being $\mathrm{Si}$ or $\mathrm{Al}$ ) on the range of $820 \mathrm{~cm}^{-1}$ was noted at different curing temperatures. However, a shift in the wave number of concrete 130 towards a lower wavelength was noticed, signifying a lower degree of silica polymerization [24]. However, with the incorporation of GGBS in mixes 2 and 3, the intensity of this vibration decreased due to the formation of $\mathrm{C}-\mathrm{S}-\mathrm{H}$ and $\mathrm{N}-\mathrm{A}-\mathrm{S}-\mathrm{H}$ gels, associated with a reduction in the amount of $\mathrm{Al}$ [25]. When samples were cured in ambient conditions, a band at $1420 \mathrm{~cm}^{-1}$ was detected. It suggested the carbonation of unreacted $\mathrm{NaOH}$, resulting in $\mathrm{Na}_{2} \mathrm{CO}_{3}[26,27]$. The stretching vibrations associated to $-\mathrm{OH}$ bending vibrations and $\mathrm{H}-\mathrm{O}-\mathrm{H}$ stretching vibrations $\left(1600-3600 \mathrm{~cm}^{-1}\right)$ were consistent throughout the mixes. These bands represented water and provided evidence of an alkali-activation reaction in geopolymer concrete [28]. 


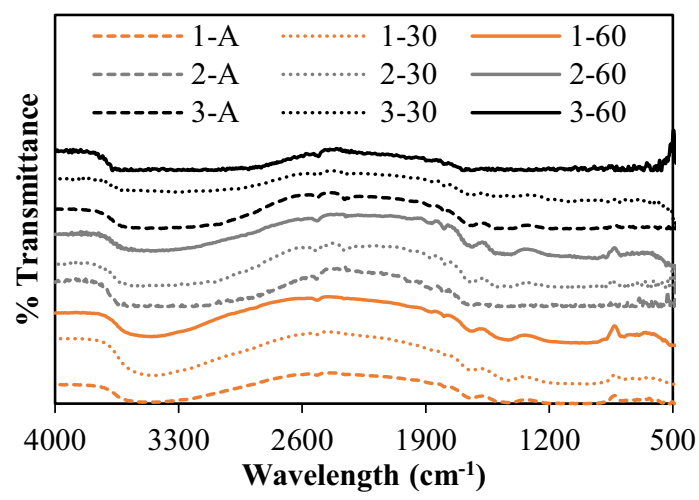

Fig. 9. FTIR spectra for geopolymer concretes after 7-day curing.

The spectra of 28-day geopolymer concrete specimens are shown in Fig. 10. An increase in $\mathrm{H}-\mathrm{O}-\mathrm{H}$ stretching vibrations at $3500 \mathrm{~cm}^{-1}$ was observed in comparison to 7-day specimens. This provided evidence that the geopolymerization reaction further developed and produced more polymerization products during subsequent curing. It is also worth noting that the intensity of these bands had increased in mix 3 with higher slag content.

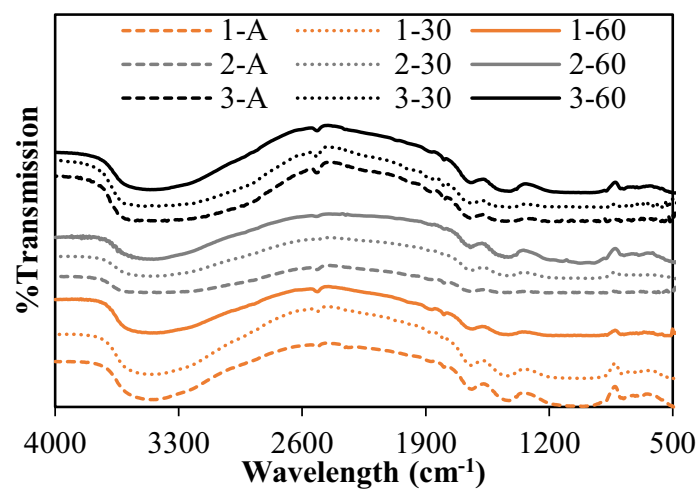

Fig. 10. FTIR spectra for 28-day geopolymer concretes.

\subsection{DSC analysis}

Fig. 11 depicts the DSC thermograms of geopolymer concrete mixes after 7 days subsequent curing. Results show an endotherm between $110^{\circ} \mathrm{C}$ and $130^{\circ} \mathrm{C}$. While some work reported it as evidence of the decomposition of combined "non-evaporable" water in the form of aluminosilicate gel [29], others work associated it to the evaporation interstitial water [30]. However, it was noticed the endothermic peak shifted towards higher temperatures (170$180^{\circ} \mathrm{C}$ ) in mixes 2 and 3 . The increase in GGBS content contributed to the degree of reactivity and reduced the setting time by developing aluminum-modified C-S-H (or C-(A)-S-H) gel $[25,27]$.

The DSC thermograms of 28-day geopolymer concretes are presented in Fig. 12. The increase in intensity of the endotherm at low temperatures indicated further geopolymerization reaction. In mix 3, an additional endotherm was detected around $100^{\circ} \mathrm{C}$, possibly due to the formation of ettringite as reported in SEM analysis. C-S-H was also identified as the broad endothermic shoulder up to $350^{\circ} \mathrm{C}$ [31]. The geopolymerization 
reaction products were highlighted as an intermix of calcium silicate hydrate and aluminosilicate hydrate in the form of a calcium aluminosilicate hydrate (C-(A)-S-H) gel.

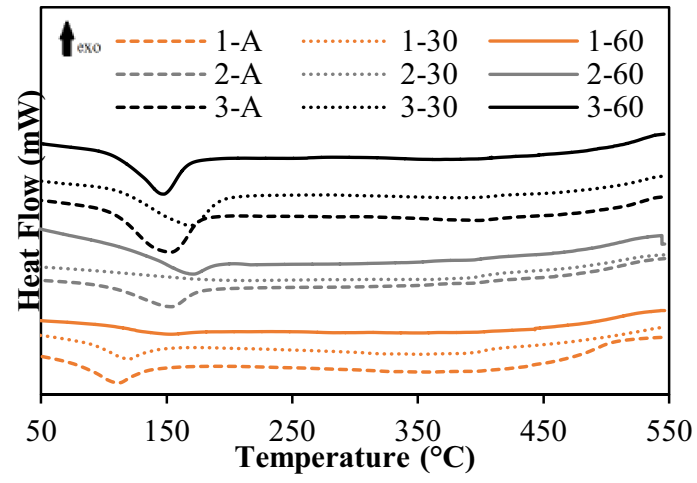

Fig. 11. DSC thermograms for 7-day geopolymer concretes.

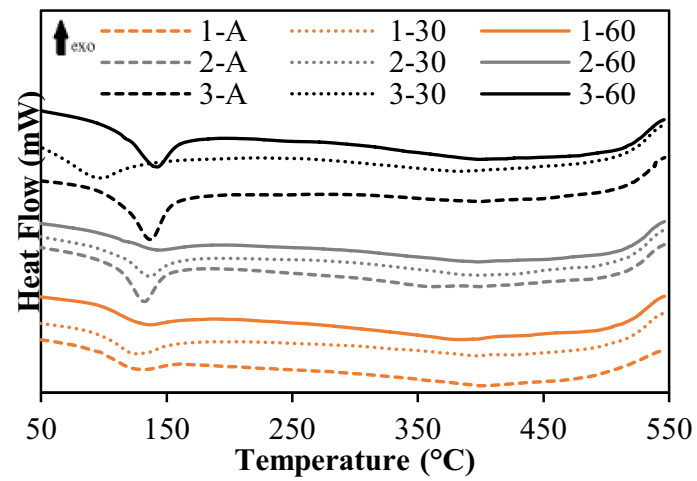

Fig. 12. DSC thermograms of geopolymer concrete after 28-day subsequent curing.

\section{Conclusion}

The microstructure of lightweight geopolymer concretes exposed to different curing temperatures has been investigated. The geopolymer concretes were prepared using GGBS, fly ash and an alkaline activation solution. The reaction products resulting from polymerization were identified. Based on the findings of this study, the following conclusions may be drawn:

1. Microstructure evaluation through SEM highlighted an amorphous geopolymeric matrix. At 7 days, the polymerization reaction was incomplete with much unreacted fly ash and slag particles, producing a weak bond at the aggregate-paste interface. The degree of reactivity however increased after 28 days with reaction products forming on the external shell of fly ash spherical particles. The addition of GGBS to concrete mixes cured at $30^{\circ} \mathrm{C}$ and $60^{\circ} \mathrm{C}$ resulted in the formation of ettringite.

2. DSC curves highlighted a major endotherm occurring in the range of $110-130^{\circ} \mathrm{C}$. It was associated to the evaporation of combined "non-evaporable" water. The water could be either interstitial or in the form of aluminosilicate hydrate gel. After 28 days subsequent curing, ettringite was detected in mix 2 and 3. Calcium silicate hydrate was detected in a broad endotherm after $350^{\circ} \mathrm{C}$. 
3. The main FTIR peaks at $820 \mathrm{~cm}^{-1}$ have been attributed to the asymmetric stretching vibration of $\mathrm{Si}-\mathrm{O}-\mathrm{Si}$ or $\mathrm{Si}-\mathrm{O}-\mathrm{Al}$ bonds. Unreacted $\mathrm{NaOH}$ could carbonate in the presence of atmospheric $\mathrm{CO}_{2}$ to produce $\mathrm{Na}_{2} \mathrm{CO}_{3}$, evidenced by the peak at 1420 $\mathrm{cm}^{-1}$. Subsequent curing led to an increase in $\mathrm{H}-\mathrm{O}-\mathrm{H}$ stretching vibrations, indicating higher degree of reaction and formation of more hydration products.

4. The coexistence of aluminum-modified C-S-H gel and N-A-S-H gel was noted, evidenced by lower intensity of vibrations at $820 \mathrm{~cm}^{-1}$ using FTIR and endothermic peaks on the range of $170^{\circ} \mathrm{C}$ using DSC. Morphologically, the two reaction products could not be easily distinguished. In fact, they were intermixed in the form of a calcium aluminosilicate hydrate (C-A-S-H) gel.

Financial support for this study was provided by the United Arab Emirates University under the grants 31N249 and 31N241. Moustafa Mansour, Mohammed Al-Mawri, Muath Bassam, Abdalla El-Hashmi, and Faisal Ali assisted with specimen preparation. Abdelrahman Alsallamin and Ehab Shehab helped in performing the microstructure analysis. Ashtech International supplied the fly ash. Emirates Cement Factory provided the ground granulated blast furnace slag and aided with chemical analysis of constituent materials.

\section{References}

1. US Geological Survey. Minerals commodity summary - cement USA: USGS; (2016) [cited 2016 October 6].

2. Afkhami B, Akbarian B, Beheshti A N, Kakaee AH, Shabani B. Energy consumption assessment in a cement production plant. Sustainable Energy Technol and Assess.10:849 (2015).

3. Thakur RN, Wu Z. Development of High-Performance Blended Cements. USA: The University of Wisconsin; (2000).

4. Davidovits J. High-Alkali Cements for 21st Century Concretes. Special Publication.144 (1994).

5. Benhelal E, Zahedi G, Shamsaei E, Bahadori A. Global strategies and potentials to curb CO2 emissions in cement industry. Journal of Cleaner Production.51:142-61 (2013).

6. Herzog HJ, Eliasson B, Kaarstad O. Capturing greenhouse gases. Scientific American.282:72-9 (2000).

7. Earth System Research Laboratory. Trends in Atmospheric Carbon Dioxide. (2013).

8. Davidovits J, editor Chemistry of Geopolymeric Systems, Terminology. 2nd International Conference on Geopolymer; Saint Qunentin; (1999).

9. Yang K-H, Song J-K, Lee J-S. Properties of alkali-activated mortar and concrete using lightweight aggregates. Materials and Structures.43(3):403-16 (2010).

10. Li Z, Ding Z, Zhang Y, editors. Development of Sustainable Cementitious Materials. International Workshop on Sustainable Development and Concrete Technology; Beijing, China; (2004).

11. Wallah SE, Rangan BV. Low-Calcium Fly Ash Based Geopolymer Concrete: LongTerm Properties. Perth, Australia: Curtin University of Technology, (2006).

12. Gourley J, Johnson G, editors. Developments in Geopolymer Precast Concrete. Fourth World Congress Geopolymer; Saint-Quentin, France; (2005).

13. Abdullah MMAB, Jamaludin L, Hussin K, Bnhussain M, Ghazali CMR, Ahmad MI. Fly Ash Porous Material using Geopolymerization Process for High Temperature Exposure. International Journal of Molecular Sciences.13(4):4388 (2012). 
14. Abdullah MMAB, Hussin K, Bnhussain M, Ismail KN, Yahya Z, Abdul Razak R. Fly Ash-based Geopolymer Lightweight Concrete Using Foaming Agent. International Journal of Molecular Sciences.13(6):7186 (2012).

15. Nath P, Sarker PK. Effect of GGBFS on setting, workability and early strength properties of fly ash geopolymer concrete cured in ambient condition. Constr Build Mater.66:16371 (2014).

16. Puertas F, Fernandez-Jimenez A. Mineralogical and microstructural characterisation of alkali-activated fly ash/slag pastes. Cem Concr Compos.25:287-92 (2003).

17. Puertas F, Martiez-Ramirez S, Alonso S, Vazquez T. Alkali-activated fly ash/slag cement strength behaviour and hydration products. Cem Concr Res.30:1625-32 (2000).

18. Akçaözoğlu S, Atiş CD. Effect of Granulated Blast Furnace Slag and fly ash addition on the strength properties of lightweight mortars containing waste PET aggregates. Constr Build Mater.25(10):4052-8 (2011).

19. Wang SD, Scrivener KL. 29Si and 27Al NMR study of alkali-activated slag. Cem Concr Res.33:769-74 (2003).

20. Das S, Yang P, Singh SS, Mertens JCE, Xiao X, Chawla N, et al. Effective properties of a fly ash geopolymer: Synergistic application of X-ray synchrotron tomography, nanoindentation, and homogenization models. Cem Concr Res.78, Part B:252-62 (2015).

21. Abdulkareem OA, Albakri MM, Hussin K, Ismail KN, Binhussain M. Mechanical and Microstructural Evaluations of Lightweight Aggregate Geopolymer Concrete before and after Exposed to Elevated Temperatures. Materials.6:4450-61 (2013).

22. Lee NK, Lee HK. Setting and mechanical properties of alkali-activated fly ash/slag concrete manufactured at room temperature. Constr Build Mater.47:1201-9 (2013).

23. Izquierdo M, Querol X, Davidovits J, Antenucci D, Nugteren H, Fernández-Pereira C. Coal fly ash-slag-based geopolymers: Microstructure and metal leaching. Journal of Hazardous Materials.166(1):561-6 (2009).

24. Mollah MYA, Yu W, Schennach R, Cocke DL. A Fourier transform infrared spectroscopic investigation of the early hydration of Portland cement and the influence of sodium lignosulfonate. Cem Concr Res.30(2):267-73 (2000).

25. Al-Majidi MH, Lampropoulos A, Cundy A, Meikle S. Development of geopolymer mortar under ambient temperature for in situ applications. Constr Build Mater.120:198211 (2016).

26. Ferone C, Colangelo F, Roviello G, Asprone D, Menna C, Balsamo A, et al. ApplicationOriented Chemical Optimization of a Metakaolin Based Geopolymer. Materials.6(5):1920 (2013).

27. Nath SK, Kumar S. Influence of iron making slags on strength and microstructure of fly ash geopolymer. Constr Build Mater.38:924-30 (2013).

28. Somna K, Jaturapitakkul C, Kajitvichyanukul P, Chindaprasirt P. NaOH-activated ground fly ash geopolymer cured at ambient temperature. Fuel.90(6):2118-24 (2011).

29. Colella C. Use of Thermal Analysis in Zeolite Research and Application. In: Rincon JM, Romero M, editors. Characterization Techniques of Glasses and Ceramics. Berlin, Heidelberg. p. 112-37: Springer Berlin Heidelberg; (1999).

30. Perera DS, Vance ER, Finnie KS, Blackford MG, Hanna JV, Cassidy DJ. Disposition of Water in Metakaolinite Based Geopolymers. Advances in Ceramic Matrix Composites XI. p. 225-36: John Wiley \& Sons, Inc.; (2006).

31. Wang K, Shah SP, Mishulovich A. Effects of curing temperature and $\mathrm{NaOH}$ addition on hydration and strength development of clinker-free CKD-fly ash binders. Cem Concr Res.34(2):299-309 (2004). 